O R I G I N A L

A R T I C L E

\title{
Reliability and validity of the overactive bladder symptom score in Hong Kong Chinese
}

\author{
MK Yiu 姚銘廣 \\ CM Li 李卓文 \\ SM Hou 侯仕明 \\ CW Wong 黃振榮 \\ S Tam 譚月明 \\ SK Chu 朱秀群
}

Key words

Reproducibility of results; Severity of illness index; Urinary bladder, overactive; Validation studies

Hong Kong Med J 2013;19:504-10 DOI: $10.12809 / \mathrm{hkmj} 133878$

Division of Urology, Department of Surgery, The University of Hong Kong, Queen Mary Hospital, Pokfulam, Hong Kong

MK Yiu, FRCS, FHKAM (Surgery) CW Wong, FCSHK, FHKAM (Surgery) Division of Urology, Department of Surgery, Pamela Youde Nethersole Eastern Hospital, Chai Wan, Hong Kong

CM Li, FRCS (Urology), FHKAM (Surgery)

Division of Urology, Department of Surgery, The Chinese University of Hong

Kong, Prince of Wales Hospital, Shatin, Hong Kong

SM Hou, FCSHK, FHKAM (Surgery)

Clinical Trials Centre, Li Ka Shing

Faculty of Medicine, The University of Hong Kong, Queen Mary Hospital, Pokfulam, Hong Kong S Tam, MMedSc, PhD

Division of Urology, Department of Surgery, Tuen Mun Hospital, Tuen Mun, Hong Kong

SK Chu, FRCS, FHKAM (Surgery)

Correspondence to: Dr MK Yiu Email: yiumk2@ha.org.hk
Objective To validate the Hong Kong Chinese translation of the Overactive Bladder Symptom Score questionnaire (OABSS-HKC).

Design Cross-sectional study.

Setting Five urology clinics of different regional hospitals in Hong Kong.

Participants The Overactive Bladder Symptom Score questionnaire was translated and culturally adapted for Hong Kong Chinese, according to the Principles of Good Practice for the Translation and Cultural Adaptation Process for Patient-Reported Outcomes Measures. Chinese-speaking patients with overactive bladder symptoms were recruited from five urology clinics. The patients completed the OABSS-HKC, a 3-day micturition diary, International Prostate Symptom Scores, and the Patient Perception of Bladder Condition questionnaires (visit 1), and again after a 2-week interval (visit 2). Test-retest reliability was evaluated by the intraclass correlation coefficient and weighted Kappa coefficient. The relationship between OABSS-HKC total scores and items in the comparison measures was evaluated using Spearman's correlation coefficients.

Results The OABSS-HKC was successfully translated and culturally adapted. Fifty-one patients completed the validation study. A high level of reliability was observed between the OABSSHKC total score answered at visit 1 and 2 for all subjects (intraclass correlation coefficient, 0.82) and among the four items answered (weighted Kappa coefficients, 0.57-0.75). The OABSS-HKC total score correlated significantly with numbers of micturitions, incontinence and urgency episodes recorded in the 3-day micturition diary, as well as the total International Prostate Symptom Scores and the Patient Perception of Bladder Condition score. However, the OABSS-HKC total score was not significantly associated with nocturia episodes, total voided volume, or number of pads used.

Conclusions The OABSS-HKC total scores are reliable and moderately valid for the quantitative evaluation of overactive bladder symptoms in Hong Kong Chinese-speaking adults.

\section{New knowledge added by this study}

- The newly translated and culturally adapted Hong Kong Chinese version of the Overactive Bladder Symptom Score questionnaire (OABSS-HKC) is reliable and moderately valid for quantitative evaluation of the relevant symptoms in local Chinese-speaking patients.

\section{Implications for clinical practice or policy}

- The existing instruments measuring overactive bladder symptoms mainly focus on their effects on daily living (not on the symptoms per se), and difficult to self-administer.

- The OABSS-HKC is an easy-to-use and validated patient-reported outcome measure for evaluation of overactive bladder symptoms.

\section{Introduction}

Overactive bladder (OAB) is initially diagnosed based only on symptoms, without recourse to tests of urodynamic functions. It comprises symptoms of urinary urgency (a prerequisite for the diagnosis), urinary frequency (daytime and nighttime) with or without urge incontinence. According to the International Continence Society (ICS) year 2002 terminology, ${ }^{1}$ localised conditions such as bladder tumours, bladder calculi, and urinary 
tract infections must first be ruled out. Moreover, $\mathrm{OAB}$, especially with incontinence, is reported to have a significant influence on quality of life (QOL) ${ }^{2,3}$

The prevalence of OAB based on ICS definitions has varied in different epidemiological studies. According to the US Census Bureau international database, worldwide OAB prevalence in 2008 was $10.7 \%$ and is expected to reach to $20.1 \%$ by $2018 .{ }^{4}$ Especially in Asia, it is expected to increase markedly (to $24.4 \%$ by 2018 ). ${ }^{4}$

According to the World Population Ageing 2009 published by the United Nations, those aged 60 years or above in Hong Kong accounted for $17.7 \%$, the median population age in 2009 being 41.4 years. ${ }^{5}$ By 2050, at least half of Hong Kong population will be aged 55 years or above and have the highest mean age in the world. With these predictions, in the near future the number of patients with $\mathrm{OAB}$ will increase substantially in Hong Kong.

Serial questionnaires measuring $O A B$ symptoms are currently available, namely: the Overactive Bladder Questionnaire, the Patient Perception of Bladder Condition (PPBC), the Urgency Questionnaire, and the Primary OAB Symptom Questionnaire. The reproducibility of these tools have been investigated, ${ }^{6,7}$ but none are employed as a patient-reported outcome (PRO) measure for symptoms and QOL. Moreover, these instruments mainly focus on the effects of $\mathrm{OAB}$ on daily living and not on $\mathrm{OAB}$ symptoms. An Overactive Bladder Symptom Composite Score (OAB-SCS), on the other hand, can quantitatively evaluate $O A B$ symptoms through the Indevus Urgency Severity Scale, which evaluates all voiding symptoms and urgency incontinences. ${ }^{8}$ However, the OAB-SCS is a tedious and difficult instrument for patients to administer as it involves a micturition diary.

The Overactive Bladder Symptom Score questionnaire (OABSS) was originally developed by Homma et $\mathrm{al}^{9}$ in 2006 to evaluate OAB symptoms. The questionnaire was developed in Japanese. Unlike other questionnaires measuring $\mathrm{OAB}$, the OABSS makes evaluation of relevant symptoms possible as a single index. An OABSS total score is the sum of scores of several items - namely: daytime frequency, nighttime frequency, urgency, and urgency incontinence-the OABSS is, therefore, regarded as a PRO measure (one-stop test) without the need to complete a 3-day micturition diary. Moreover, the OABSS has been shown to have high sensitivity for treatment-related changes in $\mathrm{OAB}$ symptoms among Japanese patients. ${ }^{10}$

To turn the original OABSS into Hong Kong Chinese (HKC), the key element was not only dependent on an accurate linguistic translation but also required a conceptual and cultural equivalence. A widely accepted international standard for

\section{膀胼過度活動症症狀評分表（中文版）的 信度和效度}

目的驗證膀胱過度活動症症狀評分表的香港中文翻譯版本 (OABSS-HKC)

設計 橫斷面研究。

安排 香港不同分區醫院的五間泌尿科診所。

參與者 根據翻譯和文化適應患者報告結果措施的良好實踐原 則，把膀胱過度活動症症狀評分表翻譯成合乎香港文 化的中文版本。五間泌尿科診所中的漢語膀胱過度活 動症患者參與本研究。患者完成了 OABSS-HKC、為 期三天的排尿日記、國際前列腺症狀評分表（IPSS ) 及患者膀胱狀況感受問卷（PPBC），並於兩週後再 完成同樣的問卷。利用組內相關系數和加權Kappa系 數評估問卷的重測信度。最後用Spearman相關系數評 估OABSS-HKC的總分和比較措施中各項的關係。

結果 成功把OABSS 翻譯成香港中文版, 並根據本港文化 改編。51名參與者完成驗證研究。所有參與者於第一 次和第二次訪問中, OABSS-HKC總分（組內相關系 數=0.82）及四個項目（加權Kappa系數=0.57-0.75） 均有高水平信度。OABSS-HKC總分與記錄在三天 排尿日記中的排尿次數、尿失禁和緊迫性發作次數 顯著相關, 亦與IPSS總分和PPBC得分明顯相關。然 而, OABSS-HKC總分與夜尿發作、總排尿量及使用 熱的數目沒有顯著關係。

結論 OABSS-HKC總分對於定量評估香港漢語膀胱過度活 動症成年患者屬可靠並適度有效。

translation and cultural adaptation (TCA) of PRO measures is the Principles of Good Practice for the Translation and Cultural Adaptation Process for Patient-Reported Outcomes Measures. ${ }^{11}$

The primary objective of this study was to evaluate the test-retest reliability of the HKC version of the OABSS (OABSS-HKC). The secondary objective was to validate the OABSS-HKC by evaluating its correlation with the existing standard $\mathrm{OAB}$ evaluation measures, namely: the 3-day micturition diary, International Prostate Symptom Scores (IPSS) and its QOL score, and the PPBC.

\section{Methods}

\section{Translation and cultural adaptation process}

The developer of the OABSS was contacted and permitted the authors to turn the OABSS Japanese version (source) into a HKC version. The source was translated and culturally adapted into the HKC version in accordance with the Principles of Good Practice for TCA Process for PRO Measures. ${ }^{11}$ The TCA process included the following steps: 
1. Learning from the developer (Dr Homma) of the source on the conceptual basis of each item of the source.

2. Independent forward translation by two translators who were native speakers of HKC and fluent in Japanese.

3. Reconciliation of the two translated versions into a reconciled $\mathrm{HKC}$ version.

4. Independent backward translation on the reconciled HKC version by two translators who were native Japanese speakers and fluent in HKC.

5. Review of back translations against the source for discrepancies. Dr Homma was consulted and resolved the difficult issues. The HKC translation was revised accordingly and the secondreconciled HKC version was produced.

6. A urologist, two other clinicians, and one urology nurse reviewed and fine-tuned the version into the third-reconciled HKC version.

7. Cognitive debriefing-the third-reconciled HKC version was self-administered by Chinesespeaking patients with $\mathrm{OAB}$ to assess their level of comprehension and cognitive equivalence of the translation. Before the cognitive debriefing study, ethics approval was obtained for conduct of the study. All patients who participated were asked to provide written informed consent prior to enrolment.

8. The cognitive debriefing results were reviewed and the translation was modified into the fourthreconciled $\mathrm{HKC}$ version.

9. After proofreading on spelling and formatting of the translation, a final OBASS-HKC was developed.

\section{The validation process}

A validation study of the final OABSS-HKC was conducted in five urology clinics of different regional hospitals serving an estimated population of 5 million in Hong Kong between October 2009 and February 2011. Male or female patients aged 18 years or older, with symptoms of OAB for at least 3 months and more than one episode of urinary urgency with or without urgency incontinence in the prior 3 days, were eligible to be screened in the study clinics. Patients were excluded if they predominantly had stress incontinence (as determined by the investigator), an indwelling catheter or were practising intermittent self-catheterization, a symptomatic urinary tract infection or chronic inflammation, had started an OAB treatment that was stopped or changed in the last 4 weeks, or had diabetic neuropathy. Written informed consent was obtained from patients prior to screening

At screening, the investigators instructed the patients on how to record information on the micturition diary for 3 days prior to visit 1 (week 0 ) and visit 2 (week 2 ). The diary recorded the number of micturitions, and episodes of urgency, incontinence, nocturia, as well as volume of each void and number of incontinence pads used for 3 days prior to each visit. Recording for 1 day started when patients woke up and ended on the following day when the patient woke up.

At visit 1, the diary was assessed by the investigator for confirmation of patient eligibility. Patients had to have at least eight micturitions per day and at least one urgency episode as per record in the diary. Patients who did not complete the 3-day micturition diary according to instructions were excluded at visit 1. Eligible patients were asked to complete the second 3-day micturition diary over 3 days prior to visit 2 . At both visits, patients completed the questionnaires, namely: the OABSS-HKC, IPSS and IPSS-QOL, and the PPBC.

During the study, indwelling catheters and intermittent self-catheterization were prohibited. Initiation of medications (namely, anticholinergics/ antispasmodics, anti-Parkinson drugs), $\alpha$-antagonists, and tricyclic antidepressants (namely, amitriptyline and imipramine) were not allowed. Patients were not allowed to change dosages of any concomitant medications, namely, antidepressants (tri-and tetracyclic), antihistamines or antimetics, loop diuretics, neuroleptics, type I antiarrhythmics, and opioids.

Ethics approval was granted for the conduct of the study at each site. The study was conducted in accordance with International Conference on Harmonisation Good Clinical Practice guidelines and Declaration of Helsinki.

A sample size was calculated in order to archive an accuracy of parameter estimate, namely OABSSHKC total score. Forty evaluable subjects were found to be required. In consideration of possible exclusions or dropout rates, the study planned to recruit up to 80 subjects. Descriptive statistics were calculated to summarise the demographic and clinical characteristics of patients. All statistical tests were two-tailed with a significance level of 0.05 . Test-retest reliability was examined by calculating the intraclass correlation coefficient (ICC) for the OABSS-HKC total score, and weighted Kappa coefficients for each individual symptom score. Spearman's correlation coefficients were calculated to assess the degree of association between the OABSS-HKC total score and individual variables recorded in the 3-day micturition diary, the IPSS total score, and scores for IPSS-QOL and PPBC at visits 1 and 2 . A correlation coefficient of 0.1 was considered small, 0.3 moderate, and $\geq 0.5$ large, following the guidelines proposed by Cohen. ${ }^{12}$

\section{Results}

\section{The translation and cultural adaptation process}

During the TCA process, only minimal cultural and 
conceptual difficulties were encountered. The difficulties were resolved and conceptual equivalence in translations was reached by going through the reconciliations. In the cognitive debriefing, five patients with $\mathrm{OAB}$ symptoms administered the third-reconciled OABSS-HKC. The patients were interviewed by the study team about their views on the questionnaire. All the patients considered that the overall relevance and clarity of the questionnaire was moderate or high. They all found the length of the questionnaire acceptable and no unclear or irrelevant item in the questionnaire. The patients had no comments on the content of the questionnaire except that two of them found the presentation of the scoring system at the bottom of the table unclear, and suggested presenting the scoring system in a table format. The presentation of the scoring system was then modified. The reconciled translations were adjusted and the final OABSS-HKC was developed (Table 1).

\section{The validation study}

\section{Disposition and background characteristics of patients}

Sixty-five patients were enrolled from a pool of approximately 900 new cases with $\mathrm{OAB}$ symptoms in approximately 15 months. Fourteen patients were excluded from the study (two were ineligible for screening, five had not completed the first 3-day micturition dairy, and seven the second micturition dairy). There were no significant differences in patient demographics and clinical characteristics between the 14 excluded patients and the remaining 51 patients.

The remaining patients in the study included $30(59 \%)$ males and 21 (41\%) females. Among them, $47(92 \%)$ patients had at least three or more urgency episodes with or without incontinence at baseline assessment. Patient demographic and clinical characteristics are summarised in Table 2.

\section{Reliability study}

A high level of reliability was observed between the OABSS-HKC total score answered at visits 1 and 2 for all subjects (ICC $=0.82 ; 95 \%$ confidence interval $[\mathrm{CI}]$, 0.71-0.89). A high level of correlation was observed among individual OABSS symptom scores between the two visits, with the weighted Kappa coefficients for the individual item of the OABSS-HKC as follows: daytime frequency, $0.57(95 \% \mathrm{Cl}, 0.32-0.83)$; nighttime frequency, 0.75 (95\% Cl, 0.64-0.87); urgency, 0.61 (95\% $\mathrm{Cl}, 0.46-0.77)$; and urgency incontinence, $0.74(95 \%$ $\mathrm{Cl}, 0.62-0.85)$.

As shown in Table 3, the ICC indicated a fairto-strong association between answers to each of the variables in the standard measures at visits 1 and 2 .
TABLE I. Hong Kong Chinese version of Overactive Bladder Symptom Score (OABSS-HKC) [膀胱過度活躍徵狀問卷]

Copyright reserved by Dr Yukio Homma and Dr Ming-kwong Yiu. The OABSS Hong Kong Chinese version may be copied and used without permission from the copyright holders only for the purpose of medical care or research of overactive bladder symptoms

以下的徵狀有多頻密? 請就您最近一星期的狀況, 選擇一個最接近的頻密程度, 並 將分數欄內相應數字圈出來。

\begin{tabular}{|c|c|c|c|}
\hline 問題 & 徵狀 & 頻密程度 & 分數 \\
\hline 1 & $\begin{array}{l}\text { 由早上起床開始至晚上睡覺為止, 大約小 } \\
\text { 便了多少次? }\end{array}$ & $\begin{array}{l}\text { 7次或以下 } \\
8 \sim 14 \text { 次 } \\
\text { 15次或以上 }\end{array}$ & $\begin{array}{l}0 \\
1 \\
2\end{array}$ \\
\hline 2 & $\begin{array}{l}\text { 由晚上睡覺至早上起床為止, 為了小便而 } \\
\text { 起床的次數大約有多少次? }\end{array}$ & $\begin{array}{l}\text { 0次 } \\
\text { 1次 } \\
\text { 2次 } \\
\text { 3次或以上 }\end{array}$ & $\begin{array}{l}0 \\
1 \\
2 \\
3\end{array}$ \\
\hline 3 & 有沒有試過突然感到尿急, 覺得難以忍受？ & $\begin{array}{l}\text { 沒有 } \\
\text { 1星期少過1次 } \\
\text { 1星期1次或以上 } \\
\text { 大約1日1 } \\
\text { 1日2 4次 } \\
\text { 1日5次或以上 }\end{array}$ & $\begin{array}{l}0 \\
1 \\
2 \\
3 \\
4 \\
5\end{array}$ \\
\hline 4 & 有沒有試過突然感到尿急而達致漏尿？ & $\begin{array}{l}\text { 沒有 } \\
\text { 1星期少過1次 } \\
\text { 1星期1次或以上 } \\
\text { 大約1日1次 } \\
\text { 1日2 4次 } \\
\text { 1日5次或以上 }\end{array}$ & $\begin{array}{l}0 \\
1 \\
2 \\
3 \\
4 \\
5\end{array}$ \\
\hline & 總分數（OABSS） & 分 & \\
\hline \multicolumn{4}{|c|}{ 有膀胱過度活躍徵狀：問題 3 的分數 $\geq 2$ 分, 並且總分數 $\geq 3$ 分 } \\
\hline \multicolumn{4}{|c|}{ 徵狀程度： 總分數 3 至5分：輕度 } \\
\hline \multicolumn{4}{|c|}{ 總分數 6至11分：中等度 } \\
\hline \multicolumn{4}{|c|}{ 總分數 $\geq 12$ 分：重度 } \\
\hline
\end{tabular}

TABLE 2. Patient demographics and background characteristics $(n=5 I)$

\begin{tabular}{lc}
\hline Parameters & No. (\%) of patients* \\
\hline Age (years) & $53 \pm 13$ \\
\hline Mean \pm standard deviation & $53(26-86)$ \\
\hline Median (range) & \\
Gender & $30(59 \%)$ \\
\hline Male & $21(41 \%)$ \\
\hline Female & \\
\hline Body mass index $\left(\mathrm{kg} / \mathrm{m}^{2}\right)$ & $24 \pm 3$ \\
\hline Mean \pm standard deviation & $24(18-34)$ \\
\hline Median (range) & \\
\hline History of overactive bladder & $11(22 \%)$ \\
\hline 3 Months - 1 year & $26(51 \%)$ \\
\hline 1-5 Years & $14(27 \%)$ \\
\hline 5 Years
\end{tabular}

No. of urgency episodes ${ }^{\dagger}$

$\begin{array}{lc}1 \text { or } 2 & 4(8 \%) \\ 3 \text { to } 5 & 17(33 \%) \\ \geq 6 & 30(59 \%)\end{array}$

* Unless otherwise stated

No. of urgency episodes with or without incontinence in the last 3 days 
TABLE 3. Test-retest reliability by intraclass correlation coefficient between variables or scores at visits I and $2^{*}$

\begin{tabular}{lll}
\hline Measure & Item & ICC (95\% Cl) \\
\hline 3-Day micturition diary & No. of micturition & $0.796(0.670-0.878)$ \\
\hline & No. of incontinence & $0.802(0.677-0.881)$ \\
& No. of urgency & $0.744(0.592-0.845)$ \\
& No. of nocturia & $0.832(0.723-0.900)$ \\
\hline IPSS & Total voided volume & $0.786(0.655-0.872)$ \\
& No. of pads used & $0.928(0.878-0.958)$ \\
\hline PPBC & Total score & $0.851(0.753-0.912)$ \\
\hline
\end{tabular}

* ICC denotes intraclass correlation coefficient, $\mathrm{CI}$ confidence interval, IPSS International Prostate Symptom Scores, PPBC Patient Perception of Bladder Condition, and QO quality of life

TABLE 4. Spearman's correlation coefficients between OABSS-HKC total score and variables in 3-day micturition diary, IPSS total score, IPSS-QOL, and PPBC at visits I and $2^{*}$

\begin{tabular}{lllc}
\hline Measures & Item & \multicolumn{1}{c}{$\begin{array}{c}\text { OABS-HKC total score } \\
\text { coefficient }\end{array}$} \\
\cline { 3 - 4 } & & Visit 1 & Visit 2 \\
\hline 3-Day micturition diary & No. of micturition & $0.422^{\dagger}$ & $0.338^{\dagger}$ \\
& No. of incontinence & $0.406^{\dagger}$ & $0.576^{\ddagger}$ \\
& No. of urgency & $0.298^{\dagger}$ & $0.439^{\dagger}$ \\
& No. of nocturia & $0.241^{\S}$ & $0.221^{\S}$ \\
& Total voided volume & $0.161^{\S}$ & $0.253^{\S}$ \\
\hline IPSS & No. of pads used & $0.233^{\S}$ & $0.101^{\S}$ \\
\hline PPBC & Total score & $0.283^{\dagger}$ & $0.323^{\dagger}$ \\
\hline & QOL score & $0.284^{\dagger}$ & $0.486^{\ddagger}$ \\
\hline
\end{tabular}

* OABSS-HKC denotes the Hong Kong Chinese version of the Overactive Bladder Symptom Score questionnaire, IPSS International Prostate Symptom Scores, QOL quality of life, and PPBC Patient Perception of Bladder Condition

$\mathrm{P}<0.05$

$P<0.001$

\& $P>0.05$

\section{Discussion}

The OABSS developed by Homma et al in $2006^{9}$ has been translated into various languages around the world, and widely employed for its utility. However, there are always reservations about a questionnaire developed by and for differing ethnic groups. This is because the symptoms and complaints expressed with a functional disorder such as OAB can vary with differing dispositions, such as social circumstances and regions, patient gender, age, individual conditions, or environments. Thus, the OABSS-HKC version was translated and culturally adapted in accordance with international guidelines. With the translated and culturally adapted OABSS-HKC, the study was conducted to evaluate whether or not the Japanese-developed OABSS was also valid for Hong Kong Chinese-speaking patients.

The test-retest reliability was high for the OABSS-HKC total score and each of the four constituents after a 2-week interval. The OABSSHKC total score was correlated with the number of micturition, incontinence and urgency episodes recorded in the 3-day micturition diary, and other measures namely: the scores for IPSS, IPSS-QOL, and PPBC. The results suggest that the OABSS-HKC is a reliable and moderately valid $\mathrm{PRO}$ measure for $\mathrm{OAB}$ symptoms. The OABSS-HKC can be an alternative to the micturition diary for $\mathrm{OAB}$ symptom assessment in case patients or caregivers who are not capable in managing a micturition diary.

One limitation of the study was that the patients' answers to the OABSS-HKC may have been influenced by what the patients recorded in the micturition diaries in the previous 3 days. We believe such influence was minimised because all the patients were asked to record the requested events on the diary when they occurred (real-time recording) during those 3 days. At the study visits, all patients were asked to recall the events that occurred in the past 1 week and not just the past 3 days and record the answers in the OABSS-HKC. The patients were not allowed to read out from the diary while filling in the OABSS-HKC. Another limitation of the study was that the weights (scale of score) given to the individual items could influence the strength of associations with items in the micturition diary.

Notably, the nocturia episodes, total urine voided volumes, and number of pads used recorded in the diary were not significantly associated with the OABSS-HKC total score. This may be explained by the kind of pads used in this study not being standardised; a strong personal preference was involved in changing of pads. In addition, there are concerns about the accuracy of the voided volumes measured by the patients and recall of nocturia episodes in the morning.

The IPSS total score in this study showed 
significant correlations with OABSS-HKC total score, and concerns elements of voiding dysfunction and bladder storage symptoms. While it was established as a questionnaire to evaluate benign prostate hyperplasia (BPH) symptoms, the relevant signs and symptoms are similar to those of $\mathrm{OAB}$ patients. To date, it is the best available scoring tool used in clinical practice for OAB. The IPSS total score and various markers are used to evaluate the potency of BPH drugs, and the OABSS total scores are sometimes used simultaneously and are reported to yield similar outcomes..$^{13,14}$

Notably, there was a strongly significant correlation between the OABSS-HKC total score and PPBC, which was similar to the findings of Homma and Gotoh. ${ }^{15}$ In another recent report by Homma et $\mathrm{al}^{10}{ }^{10}$ there was high correlation between OABSS total scores and 3-day micturition diary items, that were reported to yield high sensitivity for detecting $\mathrm{OAB}$ changes following treatment. In general, such findings are also in agreement with the results of this study and those report by Xu et al. ${ }^{16}$ Another definite limitation of the current OABSS-HKC validation study was that the responsiveness to treatment was not evaluated, but further studies to look into this are planned.

Patients with $\mathrm{OAB}$ are often classified as incontinent $(\mathrm{OAB}$ wet) or without incontinence (OAB dry). Patients with incontinence obviously have lower QOLs than those without. In the report by Homma et al, ${ }^{9}$ the OABSS total score distributions clearly differed in the two groups. Future studies in $\mathrm{OAB}$ patients need to use this classification.

\section{Conclusions}

The OABSS-HKC total score has high reproducibility and correlated with most of the variables in the micturition diary, the IPSS, and the PPBC. The OABSSHKC total score is reliable and moderately valid for quantitative evaluation of OAB symptoms of Hong Kong Chinese-speaking patients.

\section{Acknowledgements}

To all the clinical colleagues for their involvement in the review of preliminary OABSS-HKC and the cognitive debriefing study: Dr Tin-yu Chu, Dr Kwokleung Ho, and Miss Mei-sum Yim from Division of Urology, Department of Surgery, Princess Margaret Hospital, Hong Kong. Special thanks to Prof Yukio Homma, The University of Tokyo, Tokyo, in granting permission for the translation of the OABSS and providing expert advice during reconciliation of the translation.

To the following investigators and institutes participated in the validation study (RESORT-1 study): Drs Tin-yu Chu and Yi Chiu from Division of Urology, Department of Surgery, Princess Margaret Hospital; Dr Chi-kwok Chan from Division of Urology, Department of Surgery, The Chinese University of Hong Kong, Prince of Wales Hospital; Dr Winghan $\mathrm{Au}$ from Division of Urology, Department of Surgery, The University of Hong Kong, Queen Mary Hospital; Drs Chi-wai Fan and Hin Lysander Chau from Division of Urology, Department of Surgery, Pamela Youde Nethersole Eastern Hospital; Drs Chi-wai Man, Cheong Yu, Man-hung Cheung from Division of Urology, Department of Surgery, Tuen Mun Hospital.

This study was supported by a research grant of Astellas Pharma Inc., Tokyo, Japan. The authors have indicated that they have no other conflicts of interest regarding the content of this article.

\section{References}

1. Abrams P, Cardozo L, Fall M, et al. The standardization of terminology of lower urinary tract function: report from the Standardisation Sub-committee of the International Continence Society. Neurourol Urodyn 2002;21:16778. cross ref

2. Coyne K, Revicki D, Hunt T, et al. Psychometric validation of an overactive bladder symptom and health-related quality of life questionnaire: the OAB-q. Qual Life Res 2002;11:56374. cross ref

3. Homma Y, Kawabe K. Health-related quality of life of Japanese patients with overactive bladder treated with extended-release tolterodine or immediate-release oxybutynin: a randomized, placebo-controlled trial. World J Urol 2004;22:251-6. cross ref

4. Irwin DE, Kopp ZS, Agatep B, Milsom I, Abrams P. Worldwide prevalence estimates of lower urinary tract symptoms, overactive bladder, urinary incontinence and bladder outlet obstruction. BJU Int 2011;108:1132-8. cross ref

5. United Nations. World population ageing 2009. Available from: http://www.un.org/esa/population/publications/WPA2009/ WPA2009_WorkingPaper.pdf. Accessed 5 April 2012.

6. Matza LS, Thompson CL, Krasnow J, Brewster-Jordan J, Zyczynski T, Coyne KS. Test-retest reliability of four questionnaires for patients with overactive bladder: the Overactive Bladder Questionnaire, Patient Perception of Bladder Condition (PPBC), Urgency Questionnaire (UQ), and the Primary OAB Symptom Questionnaire (POSQ). Neurourol Urodyn 2005;24:215-25. cross ref

7. Coyne KS, Matza LS, Kopp Z, Abrams P. The validation of the patient perception of bladder condition (PPBC): a singleitem global measure for patients with overactive bladder. Eur Urol 2006;49:1079-86. cross ref 
8. Zinner N, Harnett M, Sabounjian L, Sandage B Jr, Dmochowski R, Staskin D. The overactive bladder-symptom composite score: a composite symptom score of toilet voids, urgency severity and urge urinary incontinence in patients with overactive bladder. J Urol 2005;173:1639-43. cross ref

9. Homma $Y$, Yoshida M, Seki N, et al. Symptom assessment tool for overactive bladder syndrome-overactive bladder symptom score. Urology 2006;68:318-23. cross ref

10. Homma Y, Kakizaki H, Yamaguchi O, et al. Assessment of overactive bladder symptoms: comparison of 3-day bladder diary and the overactive bladder symptoms score. Urology 2011;77:60-4. cross ref

11. Wild D, Grove A, Martin M, et al. Principles of Good Practice for the Translation and Cultural Adaptation Process for Patient-Reported Outcomes (PRO) Measures: report of the ISPOR Task Force for Translation and Cultural Adaptation. Value Health 2005;8:94-104. cross ref

12. Cohen J. Statistical power analysis for the behavioral sciences. 2nd ed. Philadelphia: Lawrence Erlbaum
Associates; 1988.

13. Masumori N, Tsukamoto T, Yanase $M$, Horita $H$, Aoki $M$. The add-on effect of solifenacin for patients with remaining overactive bladder after treatment with tamsulosin for lower urinary tract symptoms suggestive of benign prostatic obstruction. Adv Urol 2010;2010:205251.

14. Zaitsu M, Mikami K, Ishida N, Takeuchi T. Comparative evaluation of the safety and efficacy of long-term use of imidafenacin and solifenacin in patients with overactive bladder: a prospective, open, randomized, parallel-group trial (the LIST Study). Adv Urol 2011;2011:854697.

15. Homma Y, Gotoh M. Symptom severity and patient perceptions in overactive bladder: how are they related? BJU Int 2009;104:968-72. cross ref

16. Xu KX, Wang L, Wang XF, et al. Test-retest reliability of the overactive bladder symptom score and its correlation with other overactive bladder symptom evaluation tools among Chinese overactive bladder symptom patients. Chin J Urol 2010;11:727-31. 